\title{
Photosynthesis, Morphology, Yield, and Phytochemical Accumulation in Basil Plants Influenced by Substituting Green Light for Partial Red and/or Blue Light
}

\author{
Haijie Dou \\ Department of Horticultural Sciences, Texas A\&M University, College \\ Station, TX 77843 \\ Genhua Niu \\ Department of Horticultural Sciences, Texas A\&M AgriLife Research Center at \\ El Paso, Texas A\&M University System, 1380 A\&M Circle, El Paso, TX 79927 \\ Mengmeng Gu \\ Department of Horticultural Sciences, Texas A\&M AgriLife Extension Service, \\ College Station, TX 77843
}

Additional index words. canopy density, cryptochrome, gas exchange rate, light interception, shade avoidance response

\begin{abstract}
Green light penetrates deeper into the plant canopy because of its high transmittance and reflectance, and may potentially increase light interception and whole-canopy photosynthesis, whereas red and blue light is absorbed primarily by upper leaves. Moreover, green light induces shade avoidance responses and regulates secondary metabolism in plants. In this study, we investigated the effects of substituting partial red and/or blue light with green light on plant growth and development in basil (Ocimum basilicum) 'Improved Genovese Compact' (green) and 'Red Rubin' (purple) plants. There were four treatments: one combined red and blue $(R \& B)$ light treatment, $R_{76} B_{24}$ [the proportion of red $(R)$ and blue (B) light was $76 \%$ and $24 \%$, respectively]; and three green (G) light treatments- $R_{44} B_{24}$ $G_{32}, R_{74} B_{16} G_{10}$, and $R_{42} B_{13} G_{45}$-with green light proportions of $32 \%, 10 \%$, and $45 \%$, respectively. The experiment was conducted in a growth room and the photosynthetic photon flux density $(P P F D)$ of all treatments was set at $220 \mu \mathrm{mol} \cdot \mathrm{m}^{-2} \cdot \mathrm{s}^{-1}$ with a $16-\mathrm{h}$ photoperiod. Plants were subirrigated as needed using a nutrient solution with an electrical conductivity (EC) of $2.0 \mathrm{dS} \cdot \mathrm{m}^{-1}$ and a $\mathrm{pH}$ of 6.0. The net photosynthetic rate $\left(P_{n}\right)$ in lower leaves was unaffected by green light treatments in green basil plants, whereas in purple basil plants it increased by $59 \%$ and $45 \%$ under treatments $R_{44} B_{24} G_{32}$ and $R_{74} B_{16} G_{10}$, respectively, compared with the combined $R \& B$ light. In green basil plants, treatments $R_{44} B_{24} G_{32}$ and $R_{42} B_{13} G_{45}$ induced stem elongation, but green light treatments showed no effects on petiole elongation, leaf expansion, leaf thickness, or plant yield. In purple basil plants, treatments $R_{44} B_{24} G_{32}$ and $R_{42} B_{13} G_{45}$ induced stem elongation and decreased leaf thickness and plant yield, but only the $R_{42} B_{13} G_{45}$ treatment induced petiole elongation, and green light treatments showed no effects on leaf expansion. Concentrations of anthocyanin, phenolics, and flavonoids, and antioxidant capacity in green basil leaves showed no differences between treatments $R_{76} B_{24}$ and $R_{44} B_{24} G_{32}$, but decreased under treatments $R_{74} B_{16} G_{10}$ and $R_{42} B_{13} G_{45}$. Concentrations of phenolics and flavonoids, and antioxidant capacity in purple basil leaves showed no differences between treatments $R_{76} B_{24}$ and $R_{74} B_{16} G_{10}$, but decreased under treatments $R_{44} B_{24} G_{32}$ and $R_{42} B_{13} G_{45}$. Combining plant yield, nutritional values, and the working environment for growers, a white light with low green light proportion $(\approx 10 \%)$ is recommended for basil production in a controlled environment.
\end{abstract}

Plants sense and respond to a broad range of light spectra from ultraviolet to far-red regions, whereas photosynthetically active radiation [including blue $(400-499 \mathrm{~nm})$, green $(500-599 \mathrm{~nm})$, and red $(600-700 \mathrm{~nm})$ lights] significantly affects plant photosynthesis, morphology, and secondary metabolism (Amaki et al., 2011; Brazaityte et al., 2016). The development of lightemitting diode (LED) technology provided researchers opportunities to regulate plant light achieved greater shoot fresh weight (FW) and dry weight (DW) in a range of plant species such as lettuce (Lactuca sativa) (Martineau et al., 2012; Tamulaitis et al., 2005), radish (Raphanus sativus) (Tamulaitis et al., 2005), strawberry (Fragaria $\times$ ananassa) (Nhut et al., 2003), and lily (Lilium, 'Pesaro') (Lian et al., 2002), compared with monochromatic red or blue light. Leaf area, shoot FW, and shoot DW in spinach (Spinacia oleracea) and nonheading Chinese cabbage (Brassica campestris 'Te Ai Qing') increased under combined R\&B light compared with monochromatic red or blue light (Fan et al., 2013; Ohashi-Kaneko et al., 2007). Similarly, leaf area and shoot FW in Chinese cabbage (Brassica alboglabra) grown under combined $\mathrm{R} \& \mathrm{~B}$ light increased by $36 \%$ to $121 \%$ and $34 \%$ to $119 \%$ compared with plants grown under monochromatic blue light, respectively $(\mathrm{He}$ et al., 2015).

Compared to red and blue lights, green light is less studied because of its low absorptivity coefficient in the absorption spectra of chlorophylls compared with red or blue light. However, green light penetrates deep into the mesophyll layers at a single-leaf level and the lower leaves at a canopy level, therefore driving photosynthesis, whereas red and blue wavelengths are absorbed mostly by the upper leaves (Meng et al., 2019; Terashima et al., 2009; Wang and Folta, 2013). It was reported that the absorption of brief flashes of $2000 \mu \mathrm{mol} \cdot \mathrm{m}^{-2} \cdot \mathrm{s}^{-1}$ monochromatic blue, red, and green light from the adaxial to abaxial surface of spinach leaves was at depths of 50,100 , and $150 \mu \mathrm{m}$, respectively (Vogelmann and Han, 2000). In a living leaf or whole-plant canopy, the relative quantum efficiency of green light is 0.87 , which is slightly less than red light $(0.91)$, but greater than blue light (0.73) (Sager et al., 1988). Theoretically, quantum yield of a dense plant canopy should be more equalized under green light as a result of increased light interception by lower leaves, which could potentially increase whole-canopy photosynthesis and, subsequently, increase plant yield. In fact, Paradiso et al. (2011) validated that canopy quantum efficiency of green light was not much less than that of red light in 'Akito' rose (Rosa). Kim et al. (2004) also reported that substituting partial red light with green light increased leaf area and shoot FW and DW in 'Waldmann's Green' lettuce by $31 \%$, $45 \%$, and $47 \%$, respectively, compared with plants grown under combined R\&B light.

Green light also contributes to plant growth, which can induce shade avoidance responses (i.e., stem elongation, leaf expansion, and petiole elongation) and alter secondary metabolism in plants (Meng et al., 2019). It was reported that known photoreceptors such as phytochromes and cryptochromes can respond to green light as a result of their broad-band absorption spectrum that tails into the green light wavelength (Smith et al., 2017). Consistently, plant responses to green light showed a tendency to counteract blue or red light-induced responses, such as inhibition of stem elongation, stomatal opening, 
and anthocyanin accumulation (Talbott et al., 2006; Zhang and Folta, 2012). It is postulated that shade avoidance responses induced by green light could increase light interception by a larger plant canopy, subsequently increasing whole-plant photosynthesis and resulting in a greater plant yield. For example, leaf length and width of 'Rex' and 'Rouxai' lettuce and 'Siberian' kale plants, and shoot FW of 'Siberian' kale plants all increased under green light compared with combined R\&B light (Meng et al., 2019). Stomatal opening stimulated by blue light was reversed by green light in a range of plant species such as arabidopsis (Arabidopsis thaliana), broadbean (Vicia faba), pea (Pisum sativum), dayflower (Commelina communis), and two tobacco species (Nicotiana tabacum and N. glauca) (Frechilla et al., 2000; Talbott et al., 2002). Furthermore, increasing green light proportions significantly decreased anthocyanin concentration in arabidopsis and 'Red Sails' lettuce plants (Zhang and Folta, 2012; Zhang et al., 2011).

Inclusion of green light in growth light sources has also been shown to be beneficial for human-based diagnostics of plant health. Combined R\&B light produces a purple light that causes plants to look gray/black, making visualization of plant health status difficult for growers, whereas inclusion of green light gives plants a green appearance and makes diagnostics of pests, disease, or nutrient deficiency much easier (Smith et al., 2017). In addition, the inclusion of green light showed other beneficial effects on plant growth. For example, Bian et al. $(2016,2018)$ reported that the photosynthetic capacity (photosynthetic rate, maximum photosynthetic efficiency in dark-adapted and light-adapted leaves, and photochemical quenching) in 'Butterhead' lettuce plants decreased under continuous $\mathrm{R} \& \mathrm{~B}$ light as a result of photoinhibition, but increased in plants grown under continuous white (supplemental green light to combined $\mathrm{R} \& \mathrm{~B}$ light) light. This indicates that inclusion of green light could alleviate photoinhibition and maintain high photosynthetic capacity in plants grown under continuous R\&B light. Inclusion of green light also induced disease resistance to anthracnose (Glomerella cinglata) in 'Sachinoka' strawberry plants grown in the field (Kudo et al., 2011).

Previous studies raise the hypothesis that substituting green light for red and/or blue light may increase plant photosynthesis and yield, as well as alter plant secondary metab-

Received for publication 7 June 2019. Accepted for publication 9 July 2019.

This research was supported in part by the U.S Department of Agriculture National Institute of Food and Agriculture Hatch project TEX090450 and Texas A\&M AgriLife Research.

We appreciate the donation of LED lights from Illumitex and assistance received from Dr. Youping Sun, Christina Perez, Triston Hooks, Zhanyang Xu, and the student workers at Texas A\&M AgriLife Research Center at El Paso, TX.

G.N. is the corresponding author. E-mail: gniu@ ag.tamu.edu. olites accumulation. Therefore, in our study, we chose basil (Ocimum basilicum) as a model plant and substituted partial red and/or blue light with green light at different green light proportions to investigate the effects of green light on plant photosynthesis, morphology, growth, and secondary metabolism.

\section{Materials and Methods}

\section{Plant material and growing conditions}

The experiment was conducted in a walkin growth room with vertical grow racks in the Texas A\&M AgriLife Research Center at El Paso, TX, using green basil 'Improved Genovese Compact' and purple basil 'Red Rubin' plants (Johnny's Selected Seeds, Winslow, ME). For both cultivars, one seed per cell was sown in 72 square cell trays (cell size: length, $3.86 \mathrm{~cm}$; height, $5.72 \mathrm{~cm}$; volume, $59 \mathrm{~cm}^{3}$ ) with Metro-Mix 360 (peatmoss $41 \%$, vermiculite $34 \%$, pine bark $25 \%$; Sun Gro ${ }^{\circledR}$ Horticulture, Bellevue, WA). All trays were put under mist in a greenhouse for germination. Seedlings were moved out from beneath the mist after germination and were grown in a greenhouse for 2 weeks. Seedlings were then transplanted to 4 -inch ${ }^{2}$ pots (length, $9.52 \mathrm{~cm}$; height, $8.26 \mathrm{~cm}$; volume, $574 \mathrm{~cm}^{3}$ ) with Metro-Mix 360 when roots were visible on the outside of the plug root ball. Uniform plants were selected and moved to the walk-in growth room for different treatments. A vertical grow rack with four shelves was used, and each shelf was designated with one treatment.

All plants were subirrigated manually with a nutrient solution containing 1.88 $\mathrm{g} \cdot \mathrm{L}^{-1} \quad(277.5 \mathrm{ppm} \mathrm{N}) 15 \mathrm{~N}-2.2 \mathrm{P}-12.5 \mathrm{~K}$ (Peters 15-5-15 Ca-Mg Special; The Scotts Company, Marysville, $\mathrm{OH}$ ) as needed. The nutrient solution was mixed and stored in a 100-gallon tank with a lid, and $\mathrm{EC}$ and $\mathrm{pH}$ were adjusted to $2.01 \pm$ $0.06 \mathrm{dS} \cdot \mathrm{m}^{-1}$ and $5.98 \pm 0.03$, respectively, using an EC/pH meter (Model B-173; Horiba, Ltd., Kyoto, Japan). Planting density of both basil cultivars was 79 plants/ $\mathrm{m}^{2}$. Plant canopy temperature of each treatment was recorded every $30 \mathrm{~min}$ using a type $\mathrm{T}$ thermocouple connected to a data logger (CR1000; Campbell Scientific, Logan, UT). The average plant canopy temperature of four treatments throughout the experiment period was $24.0 \pm 0.15 / 21.6$ $\pm 0.18{ }^{\circ} \mathrm{C}$ day/night. The carbon dioxide $\left(\mathrm{CO}_{2}\right)$ concentration in the growth room was recorded (LI-830; LI-COR, Lincoln, $\mathrm{NE})$ every $5 \mathrm{~min}$, and the average $\mathrm{CO}_{2}$ concentration throughout the experiment was $418 \pm 8 \mu \mathrm{mol} \cdot \mathrm{mol}^{-1}$. Mechanical mini fans (LS1225A-X; AC Infinity, City of Industry, CA) were used for air circulation to achieve uniform temperatures across treatments. All plants were harvested when plant height reached about $25 \mathrm{~cm}$, which was 21 and $28 \mathrm{~d}$ after treatment (42 and $53 \mathrm{~d}$ after sowing) for green and purple basil plants, respectively. There were 12 plants per treatment for each experiment.

\section{Green light treatments}

There were four different light-quality treatments: the combined R\&B light treatment as the control, $\mathrm{R}_{76} \mathrm{~B}_{24}$ (the proportion of red and blue light was $76 \%$ and $24 \%$, respectively; model GEHL48HPPB, Hort Americas, Bedford, TX), substituting partial red light with green light; $\mathrm{R}_{44} \mathrm{~B}_{24} \mathrm{G}_{32}$, reducing the red light proportion from $76 \%$ to $44 \%$ with the addition of $32 \%$ green light (ESW X6; Illumitex, Austin, TX), substituting partial blue light with green light; $\mathrm{R}_{74} \mathrm{~B}_{16} \mathrm{G}_{10}$, reducing the blue light proportion from $24 \%$ to $16 \%$, with the addition of $10 \%$ green light (ESW F3; Illumitex), and substituting partial red and blue lights with green light; $\mathrm{R}_{42} \mathrm{~B}_{13} \mathrm{G}_{45}$, reducing both red and blue light proportions with the addition of $45 \%$ green light (model GEHL48HWTB; Hort Americas, Bedford, TX) (Table 1, Fig. 1). PPFD of each treatment was set at the same level of $220 \pm 10$ $\mu \mathrm{mol} \cdot \mathrm{m}^{-2} \cdot \mathrm{s}^{-1}$ with a $16-\mathrm{h}$ photoperiod, and $P P F D$ was measured $15 \mathrm{~cm}$ underneath the light sources at nine spots for each treatment using a PS-100 spectroradiometer (Apogee Instruments, Logan, UT). To minimize light distribution being disproportionate within each treatment, all plants were rearranged systematically every $3 \mathrm{~d}$.

\section{Measurements}

Gas exchange rates. A portable gas exchange analyzer (CIRAS-3; PP Systems International, Amesbury, MA) was used to measure the photosynthetic capacity of basil leaves at harvest, including comparative $P_{n}$, the transpiration rate $(\mathrm{E})$, and stomatal conductance $\left(g_{\mathrm{S}}\right)$. A PLC3 leaf cuvette (PP System International, Amesbury, MA) with LED light unit (white light, in which the proportion of red, blue, and green light was $38 \%, 25 \%$, and $37 \%$, respectively) was used, and $P P F D$, relative air humidity, and $\mathrm{CO}_{2}$

Table 1. Light spectral distribution of different light-quality treatments: $\mathrm{R}_{76} \mathrm{~B}_{24}, \mathrm{R}_{74} \mathrm{~B}_{16} \mathrm{G}_{10}, \mathrm{R}_{44} \mathrm{~B}_{24} \mathrm{G}_{32}$, and $\mathrm{R}_{42} \mathrm{~B}_{13} \mathrm{G}_{45}$.

\begin{tabular}{lcccc}
\hline & \multicolumn{4}{c}{ Single-band photon flux density $\left(\mu \mathrm{mol} \cdot \mathrm{m}^{-2} \cdot \mathrm{s}^{-1}\right)$} \\
\cline { 2 - 5 } Wavelength & $\mathrm{R}_{76} \mathrm{~B}_{24}$ & $\mathrm{R}_{44} \mathrm{~B}_{24} \mathrm{G}_{32}$ & $\mathrm{R}_{74} \mathrm{~B}_{16} \mathrm{G}_{10}$ & $\mathrm{R}_{42} \mathrm{~B}_{13} \mathrm{G}_{45}$ \\
\hline Blue & 53 & 54 & 36 & 28 \\
Green & - & 70 & 22 & 98 \\
Red & 169 & 97 & 165 & 93 \\
$P P F D^{z}$ & 222 & 221 & 223 & 219 \\
\hline
\end{tabular}

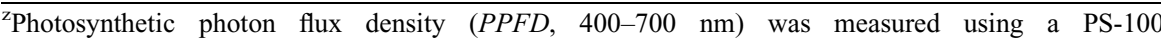
spectroradiometer (Apogee Instruments, Logan, UT).

Subscript numbers indicate the proportions of red $(\mathrm{R}, 600-699 \mathrm{~nm})$, blue $(\mathrm{B}, 400-499 \mathrm{~nm})$, and green $(\mathrm{G}$, $500-599 \mathrm{~nm}$ ) light in the total light intensity. 


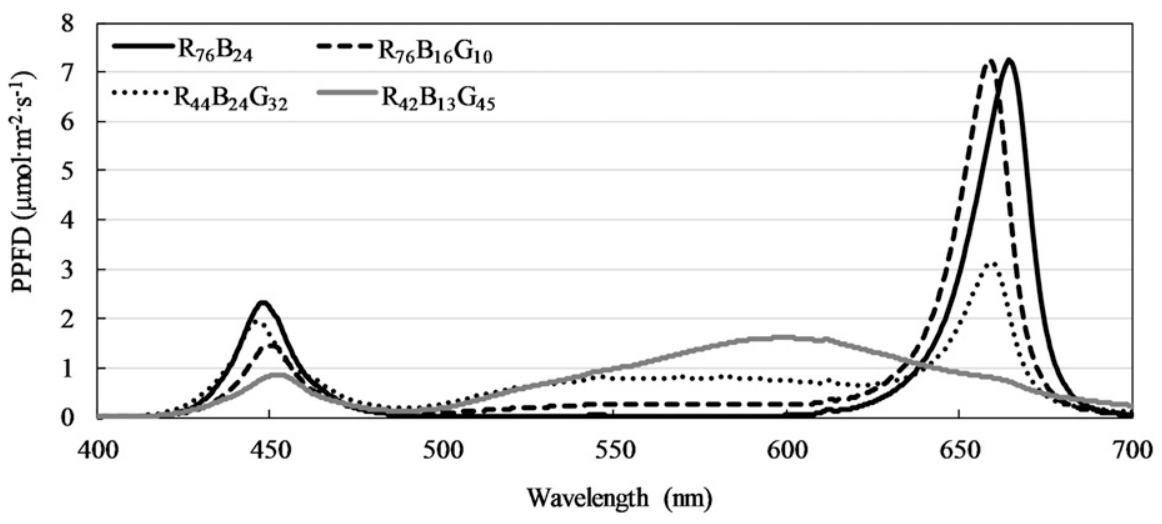

Fig. 1. Light spectral distribution of four light-quality treatments: $R_{76} B_{24}$ [subscript numbers indicate the proportions of red (R, 600-699 nm), blue (B, 400-499 nm), and green (G, 500-599 nm) light in the total light intensity], $\mathrm{R}_{74} \mathrm{~B}_{16} \mathrm{G}_{10}, \mathrm{R}_{44} \mathrm{~B}_{24} \mathrm{G}_{32}$, and $\mathrm{R}_{42} \mathrm{~B}_{13} \mathrm{G}_{45}$. Photosynthetic photon flux density $(P P F D ; 400-700 \mathrm{~nm})$ and light spectral distribution were measured using a PS-100 spectroradiometer (Apogee Instruments, Logan, UT).

concentration inside the leaf chamber were kept constant at $800 \mu \mathrm{mol} \cdot \mathrm{m}^{-2} \cdot \mathrm{s}^{-1}, 50 \%$, and $390 \mu \mathrm{mol} \cdot \mathrm{mol}^{-1}$, respectively. The third and fifth pair of leaves from the top were used for measuring the upper and lower leaves gas exchange rate, respectively, in both green and purple basil plants. Measurements were taken when $\mathrm{P}_{\mathrm{n}}$ reached a steady state.

Relative chlorophyll content. The soilplant analysis development (SPAD) index of basil leaves was measured at harvest to quantify relative chlorophyll content in basil leaves using a chlorophyll meter SPAD-502 (Konica-Minolta Co., Ltd., Osaka, Japan). The third pair of leaves from the top were used for measurement. Three measurements were taken for each plant and the average was recorded for data analysis.

Growth characteristics. Growth characteristics such as plant height, plant width (average of the widest point of plant canopy and its perpendicular width), and number of internodes were recorded at harvest. Five plants per treatment were selected randomly for measurement. Leaf area was measured using a leaf area meter (LI-3100; LI-COR), and shoot FW was recorded at harvest. Specific leaf area was calculated (leaf area per unit leaf DW) and used as an indicator of leaf thickness. Shoot tissues were dried at $80^{\circ} \mathrm{C}$ in a drying oven (Grieve, Round Lake, IL) for $3 \mathrm{~d}$ to determine the shoot DW and root DW.

Secondary metabolites. Five plants were selected randomly at harvest for the measurement of secondary metabolites in basil leaves, including concentrations of anthocyanin, phenolics, and flavonoids, and antioxidant capacity. Fresh basil leaves were collected in a cooler and stored immediately in a deep freezer (IU1786A; Thermo Fisher Scientific, Marietta, $\mathrm{OH})$ at $-80{ }^{\circ} \mathrm{C}$ until phytochemical analysis.

Extraction. About $2 \mathrm{~g}$ fresh basil leaves were ground in liquid nitrogen and extracted with $15 \mathrm{~mL} 1 \%$ acidified methanol at $4{ }^{\circ} \mathrm{C}$ in darkness. After overnight extraction, the mixture was centrifuged (Sorvall RC 6 Plus
Centrifuge; Thermo Fisher Scientific, Madison, WI) at $13,200 \mathrm{rpm}\left(26,669 g_{\mathrm{n}}\right)$ for 15 min, and the supernatant was collected for phytochemical analysis (Xu and Mou, 2016).

Anthocyanin analysis. Absorbance of the extract collected from extraction was measured at $530 \mathrm{~nm}$ vs. an acidified methanol $(1 \%)$ blank, using a spectrophotometer (Genesys 10S ultraviolet/ Vis; Thermo Fisher Scientific, Madison, WI). Because the extracts were prepared from leaf tissues maintained at $-80{ }^{\circ} \mathrm{C}$ and did not undergo extensive processing or significant browning, a $\mathrm{pH}$ differential method for anthocyanin content was considered unnecessary (Connor et al., 2002). Anthocyanin concentration was expressed as milligrams cyanidin-3-glucoside equivalent per $100 \mathrm{~g} \mathrm{FW}$ of basil leaves using a molar extinction coefficient of 29,600, which was stated as the following (Connor et al., 2002):

Anthocyanin concentration $\left(\mathrm{mg} \cdot 100 \mathrm{~g}^{-1} \mathrm{FW}\right)$

$$
=\frac{V \times n \times M \times A \times 100}{\varepsilon \times m},
$$

where $V$ is the volume of extracted liquid (measured in milliliters), $n$ is the dilution factor, $M$ is the molecular weight of cyaniding3-glucoside (449.2), $A$ is the absorbance at $530 \mathrm{~nm}, \varepsilon$ is the molar extinction coefficient $(29,600)$, and $m$ is the weight of the sample

Phenolics analysis. Total phenolics concentration of basil leaves was determined using the modified Folin-Ciocalteu reagent method (Xu and Mou, 2016) as follows: A $100-\mu \mathrm{L}$ extraction sample was added to a mixture of $150 \mu \mathrm{L}$ distilled water and $750 \mu \mathrm{L} 1 / 10$ dilution Folin-Ciocalteu reagent. After a 6-min reaction, $600 \mu \mathrm{L} 7.5 \% \quad \mathrm{Na}_{2} \mathrm{CO}_{3}$ was added and the mixture was incubated at $45^{\circ} \mathrm{C}$ in a water bath for $10 \mathrm{~min}$. When the mixture temperature cooled to room temperature, its absorbance was measured at $725 \mathrm{~nm}$ using a microplate reader (ELx800; BioTek, Winooski, VT). Results are expressed as milligrams of gallic acid equivalent per gram $\mathrm{FW}$ of basil leaves.
Flavonoids analysis. Total flavonoid concentration of basil leaves was determined (Dou et al., 2018) as follows: A $20-\mu \mathrm{L}$ extraction sample was added to a mixture of $85 \mu \mathrm{L}$ distilled water and $5 \mu \mathrm{L} 5 \% \mathrm{NaNO}_{2}$. After a 6-min reaction, $10 \mu \mathrm{L}$ of $10 \% \mathrm{AlCl}_{3}$ $.6 \mathrm{H}_{2} \mathrm{O}$ was added to the mixture. After another 5-min reaction, $35 \mu \mathrm{L}$ of $1 \mathrm{M} \mathrm{NaOH}$ and $20 \mu \mathrm{L}$ distilled water were added to the mixture, and its absorbance was measured at $520 \mathrm{~nm}$ using the aforementioned microplate reader. Results are expressed as milligrams of $(+)$-catechin hydrate equivalent per gram FW of basil leaves.

Antioxidant capacity analysis. Antioxidant capacity of plant leaves was measured using the 2,2' -azino-bis (3-ethylbenzothiazoline-6sulfonic acid) (ABTS) method (Arnao et al., 2001) as follows: A mixture of $150-\mathrm{mL}$ basil leaf extracts was added to $2.85 \mathrm{~mL} \mathrm{\textrm {ABTS } ^ { + }}$ solution and was incubated at room temperature for $10 \mathrm{~min}$. Absorbance of the mixture was measured at $734 \mathrm{~nm}$ using the aforementioned spectrophotometer. Antioxidant capacity of basil leaves is expressed as milligrams of Trolox equivalent antioxidant capacity per 100 grams FW of basil leaves.

\section{Statistical analysis}

One-way analysis of variance was conducted to analyze the effects of light-quality treatments on all measured parameters. Mean comparison among treatments was conducted using Student's $t$ test $(P<0.05)$. All statistical analyses were performed using JMP software (version 13; SAS Institute Inc., Cary, NC).

\section{Results}

Photosynthetic capacity and chlorophyll content. In green basil plants, comparative $\mathrm{P}_{\mathrm{n}}$ of the upper leaves was the greatest under the combined R\&B light treatment-namely, $\mathrm{R}_{76} \mathrm{~B}_{24}$ - and it showed no differences among treatments in the lower leaves (Fig. 2A). Green light treatments showed no effects on comparative $\mathrm{E}$ and $g_{\mathrm{S}}$ in green basil plants regardless of leaf position (Fig. $2 \mathrm{~B}$ and $\mathrm{C}$ ). In purple basil plants, comparative $\mathrm{P}_{\mathrm{n}}, \mathrm{E}$, and $g_{\mathrm{S}}$ of the upper leaves showed a similar trend, which was greater under treatments without green light and under treatments with less green light proportions - namely, $\mathrm{R}_{76} \mathrm{~B}_{24}$, $\mathrm{R}_{44} \mathrm{~B}_{24} \mathrm{G}_{32}$, and $\mathrm{R}_{74} \mathrm{~B}_{16} \mathrm{G}_{10}$ - and less with the greatest green light proportion $\left(\mathrm{R}_{42} \mathrm{~B}_{13} \mathrm{G}_{45}\right)$ (Fig. $2 \mathrm{~A}-\mathrm{C}$ ). In contrast, comparative $\mathrm{P}_{\mathrm{n}}$ of the lower leaves in purple basil plants increased under treatments $\mathrm{R}_{44} \mathrm{~B}_{24} \mathrm{G}_{32}$ and $\mathrm{R}_{74} \mathrm{~B}_{16} \mathrm{G}_{10}$ compared with plants grown under treatments $\mathrm{R}_{76} \mathrm{~B}_{24}$ or $\mathrm{R}_{42} \mathrm{~B}_{13} \mathrm{G}_{45}$ (Fig. 2A), whereas comparative $\mathrm{E}$ and $g_{\mathrm{S}}$ was the greatest under $\mathrm{R}_{44} \mathrm{~B}_{24} \mathrm{G}_{32}$, followed by $\mathrm{R}_{74} \mathrm{~B}_{16} \mathrm{G}_{10}$ and $\mathrm{R}_{76} \mathrm{~B}_{24}$, and the least under $\mathrm{R}_{42} \mathrm{~B}_{13} \mathrm{G}_{45}$ (Fig. 2B and $\mathrm{C}$ ). Green light treatments showed no effects on SPAD reading in green basil plants, whereas in purple basil plants the SPAD reading was the greatest under $\mathrm{R}_{76} \mathrm{~B}_{24}$, followed by $\mathrm{R}_{44} \mathrm{~B}_{24} \mathrm{G}_{32}$ and $\mathrm{R}_{74} \mathrm{~B}_{16} \mathrm{G}_{10}$, and the least under $\mathrm{R}_{42} \mathrm{~B}_{13} \mathrm{G}_{45}$ (Fig. 3). 

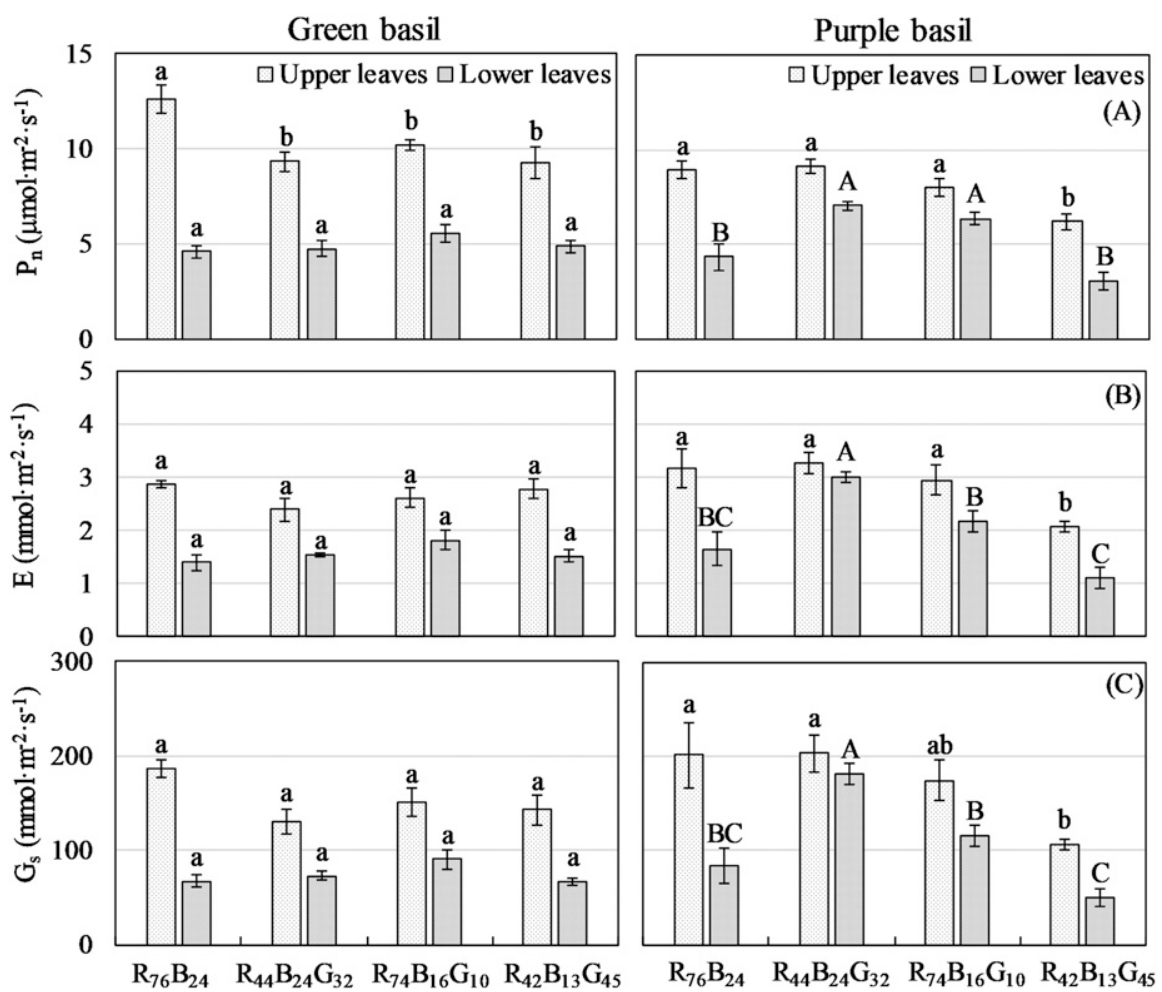

Fig. 2. Net photosynthetic rate $\left(\mathrm{P}_{\mathrm{n}}\right)(\mathbf{A})$, transpiration rate $(\mathrm{E})(\mathbf{B})$, and stomatal conductance $\left(g_{\mathrm{s}}\right)(\mathbf{C})$ of green basil 'Improved Genovese Compact' and purple basil 'Red Rubin' plants grown under different light-quality treatments: including $\mathrm{R}_{76} \mathrm{~B}_{24}, \mathrm{R}_{44} \mathrm{~B}_{24} \mathrm{G}_{32}, \mathrm{R}_{74} \mathrm{~B}_{16} \mathrm{G}_{10}$, and $\mathrm{R}_{42} \mathrm{~B}_{13} \mathrm{G}_{45}$. Means followed by the same lower- and uppercase letters are not significantly different for green and purple basil plants, respectively, according to Student's $t$ mean comparison $(P<0.05)$. Bars represent SE.

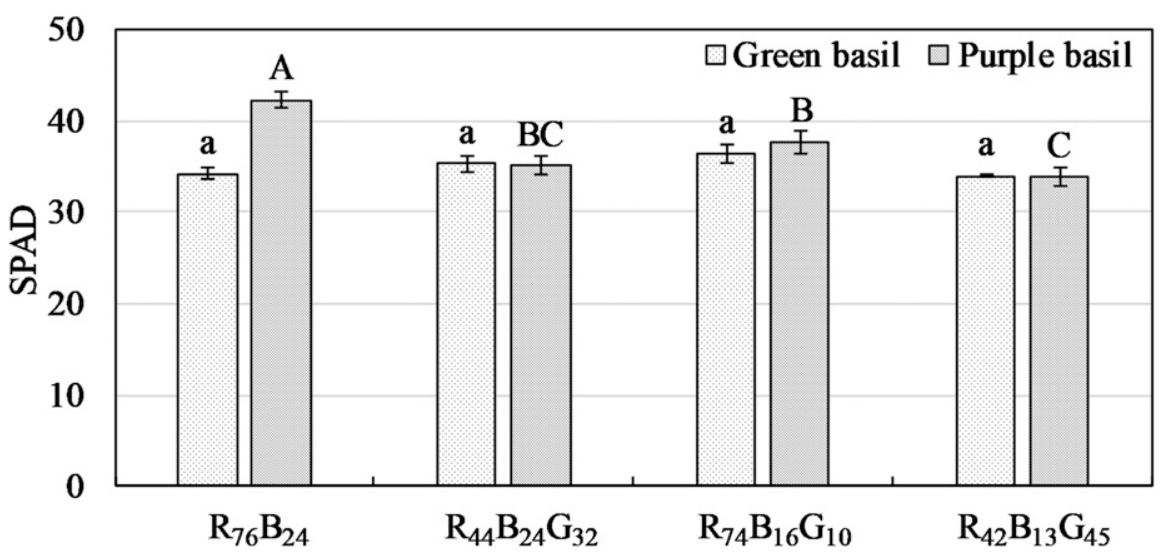

Fig. 3. Soil-plant analysis development (SPAD) of green basil 'Improved Genovese Compact' and purple basil 'Red Rubin' plants grown under different light-quality treatments: $R_{76} B_{24}, R_{44} B_{24} G_{32}, R_{74} B_{16} G_{10}$, and $\mathrm{R}_{42} \mathrm{~B}_{13} \mathrm{G}_{45}$. Means followed by the same lower- and uppercase letters are not significantly different for green and purple basil plants, respectively, according to Student's $t$ mean comparison $(P<0.05)$. Bars represent SE.

Plant growth and yield. Plant height in green and purple basil plants both increased under treatments with greater green light proportions (namely, $\mathrm{R}_{44} \mathrm{~B}_{24} \mathrm{G}_{32}$ and $\mathrm{R}_{42} \mathrm{~B}_{13} \mathrm{G}_{45}$ ) compared with $\mathrm{R}_{76} \mathrm{~B}_{24}$ and $\mathrm{R}_{74} \mathrm{~B}_{16} \mathrm{G}_{10}$ (Fig. 4A). Plant width (Fig. 4B), leaf area (Fig. 4C), and leaf thickness (Fig. 4D) showed no differences among treatments in green basil plants. In purple basil plants, plant width increased by $15 \%$ to $18 \%$ under $\mathrm{R}_{42} \mathrm{~B}_{13} \mathrm{G}_{45}$ compared with the other treatments (Fig. 4B). Leaf area in purple basil plants showed no differences among treatments (Fig. 4C), whereas leaf thickness decreased with increasing green light proportions, with the greatest under $\mathrm{R}_{76} \mathrm{~B}_{24}$, followed by $\mathrm{R}_{74} \mathrm{~B}_{16} \mathrm{G}_{10}$, and the least under $\mathrm{R}_{44} \mathrm{~B}_{24} \mathrm{G}_{32}$ and $\mathrm{R}_{42} \mathrm{~B}_{13} \mathrm{G}_{45}$ (Fig. $4 \mathrm{C})$. The number of internodes in green and purple basil plants were five and seven, respectively (data not shown).

Shoot FW and DW in green basil plants showed no differences among treatments (Fig. 5A). In purple basil plants, shoot FW and DW showed a similar trend, which was greater under treatments without green light or with the least green light proportion: $\mathrm{R}_{76} \mathrm{~B}_{24}$ and $\mathrm{R}_{74} \mathrm{~B}_{16} \mathrm{G}_{10}$ compared with $\mathrm{R}_{44} \mathrm{~B}_{24} \mathrm{G}_{32}$ and $\mathrm{R}_{42} \mathrm{~B}_{13} \mathrm{G}_{45}$ (Fig. 5B). Specifically, shoot $\mathrm{FW}$ in purple basil plants under $\mathrm{R}_{76} \mathrm{~B}_{24}$ and $\mathrm{R}_{74} \mathrm{~B}_{16} \mathrm{G}_{10}$ was $32 \%$ and $30 \%$ greater, respectively, compared with plants grown under $\mathrm{R}_{42} \mathrm{~B}_{13} \mathrm{G}_{45}$.

Accumulation of secondary metabolites. In green basil plants, concentrations of phenolics and flavonoids, and antioxidant capacity decreased under $\mathrm{R}_{74} \mathrm{~B}_{16} \mathrm{G}_{10}$ and $\mathrm{R}_{42} \mathrm{~B}_{13} \mathrm{G}_{45}$ compared with $\mathrm{R}_{76} \mathrm{~B}_{24}$ and $\mathrm{R}_{44} \mathrm{~B}_{24} \mathrm{G}_{32}$, whereas anthocyanin concentration decreased under $\mathrm{R}_{42} \mathrm{~B}_{13} \mathrm{G}_{45}$ (Table 2). Specifically, concentrations of anthocyanin, phenolics, and flavonoids, and antioxidant capacity in green basil plants grown under $\mathrm{R}_{76} \mathrm{~B}_{24}$ was $17 \%, 18 \%$, $15 \%$, and $20 \%$ greater, respectively, compared with plants grown under $\mathrm{R}_{42} \mathrm{~B}_{13} \mathrm{G}_{45}$. In purple basil plants, concentrations of phenolics and flavonoids, and antioxidant capacity decreased under $\mathrm{R}_{44} \mathrm{~B}_{24} \mathrm{G}_{32}$ and $\mathrm{R}_{42} \mathrm{~B}_{13} \mathrm{G}_{45}$, respectively, compared with $\mathrm{R}_{76} \mathrm{~B}_{24}$ and $\mathrm{R}_{74} \mathrm{~B}_{16} \mathrm{G}_{10}$, whereas anthocyanin concentration was not influenced by green light treatments (Table 2).

The total amount of phytochemicals per plant in green basil plants decreased by $17 \%$ to $21 \%$ under green light treatments (Table 3 ). In purple basil plants, total amounts of anthocyanin, phenolics, and flavonoids per plant decreased with increasing green light proportions, which were the greatest under $\mathrm{R}_{76} \mathrm{~B}_{24}$ and $\mathrm{R}_{74} \mathrm{~B}_{16} \mathrm{G}_{10}$, followed by $\mathrm{R}_{44} \mathrm{~B}_{24} \mathrm{G}_{32}$, and the least under $\mathrm{R}_{42} \mathrm{~B}_{13} \mathrm{G}_{45}$ (Table 3). The total amount of antioxidant capacity per plant in purple basil plants was the greatest under $\mathrm{R}_{74} \mathrm{~B}_{16} \mathrm{G}_{10}$, which was $5 \%, 41 \%$, and $63 \%$ greater compared with plants grown under $\mathrm{R}_{76} \mathrm{~B}_{24}, \mathrm{R}_{44} \mathrm{~B}_{24} \mathrm{G}_{32}$, and $\mathrm{R}_{42} \mathrm{~B}_{13} \mathrm{G}_{45}$, respectively (Table 3 ).

\section{Discussion}

Substituting green light for red or blue light increased photosynthesis in the lower level plant canopy. Red and blue lights are strongly absorbed in upper leaves, whereas green light, which is hard for chloroplasts to absorb, penetrates and is absorbed by the chloroplasts in lower leaves (Terashima et al., 2009). In an open field, just $\leq 0.5 \%$ of blue and $\leq 2.1 \%$ of red light from above the canopy penetrated through to the bottom leaves, whereas up to $6.5 \%$ of green light reached leaves at the bottom (Kasperbauer, 1971). This resulted in increased $P P F D$ in the lower level plant canopy under light sources with green light compared with red and/or blue light; and, accordingly, resulted in different patterns in comparative $\mathrm{P}_{\mathrm{n}}$ between the upper and lower leaves. Under green light treatments, contrary to decreased $\mathrm{P}_{\mathrm{n}}$ in the upper leaves, $P_{n}$ in the lower leaves was equal to or greater than plants grown under combined R\&B light in both basil cultivars (Fig. 2A). In the upper leaves, decreased $P_{n}$ by green light contributed to, at least in part, green light reversing blue light-induced stomatal opening and chloroplast synthesis, which has been found in a diversity of plant 

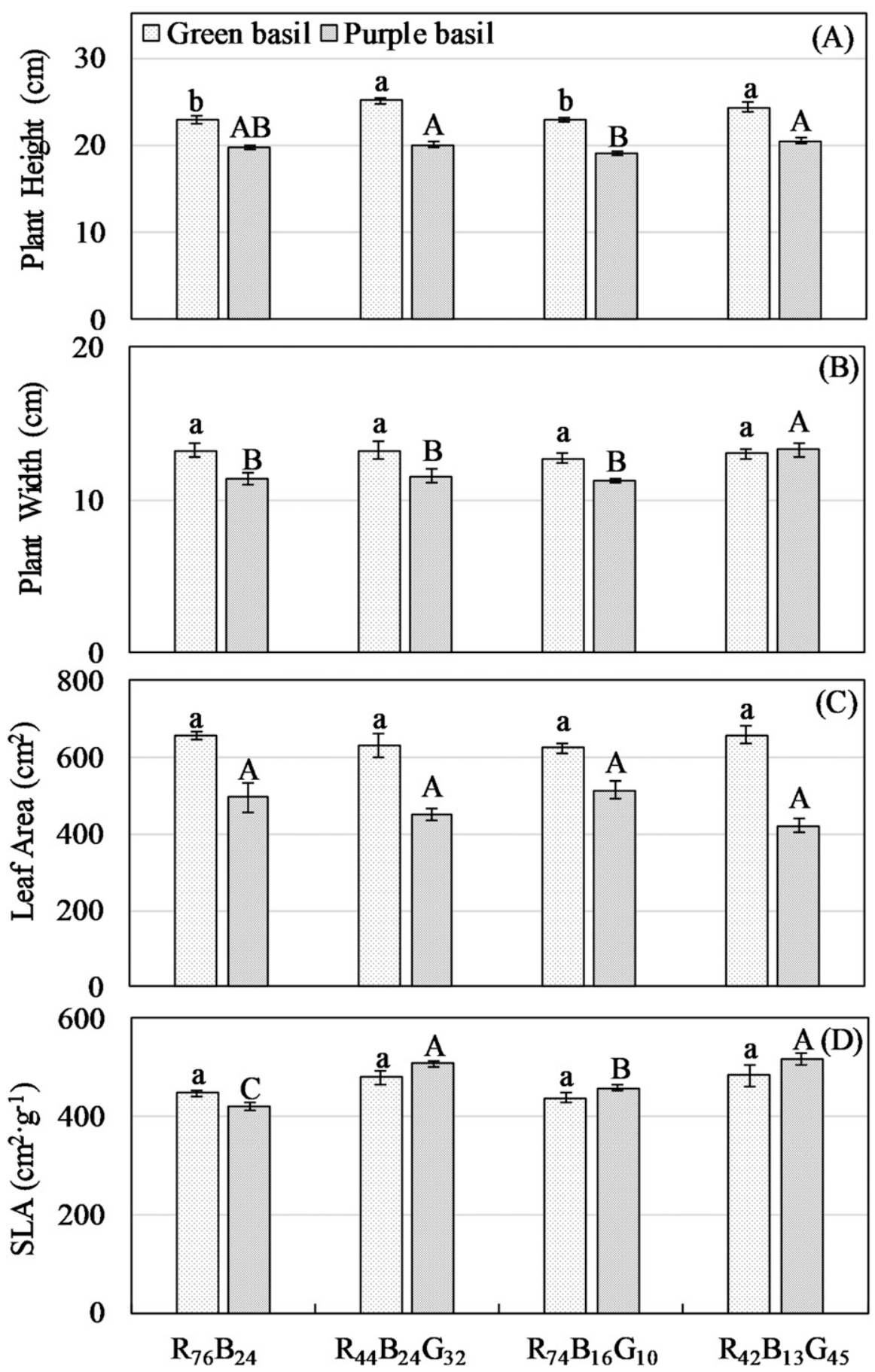

Fig. 4. Plant height (A), plant width (B), leaf area (C), and specific leaf area (SLA) (D) of green basil 'Improved Genovese Compact' and purple basil 'Red Rubin' plants grown under different light-quality treatments: $R_{76} B_{24}, R_{44} B_{24} G_{32}, R_{74} B_{16} G_{10}$, and $R_{42} B_{13} G_{45}$. Means followed by the same lower- and uppercase letters are not significantly different for green and purple basil plants, respectively, according to Student's $t$ mean comparison $(P<0.05)$. Bars represent SE.

species (Talbott et al., 2002, 2006), and was also confirmed in purple basil plants in our study (Figs. 2C and 3). In particular, the flavin chromophore of cryptochrome is driven to a biologically active semireduced form by blue light; this semireduced form is shifted to a deactivated reduced state by the absorption of green light (Banerjee et al., 2007; Bouly et al., 2007). The deactivation of cryptochrome by green light removes the signal for suppression of abscisic acid pro- fixation in the upper layer of spinach leaves (upper epidermal layer and palisade mesophyll) decreased under green light compared with red or blue light, but increased in deeper layers of the leaf. The transmission of green light deeper into the plant canopy could allow carbon fixation to continue, whereas upper leaf photosynthesis is suppressed as a result of photoinhibition under greater $P P F D$ levels or continuous light (Bian et al., 2016, 2018). Specifically, under greater PPFDs, nonphotochemical quenching could be engaged in upper leaves, whereas in lower leaves, penetrating green light could drive photosynthesis efficiently. Such coactions of nonphotochemical quenching and photosynthesis driven by green light allow carbon fixation to continue efficiently even under strong light (Sun et al., 1998).

Plant photosynthetic responses to green light varied between green and purple basil plants. In upper leaves, comparative $P_{n}$ in purple basil plants was less negatively affected by green light than in green basil plants; in lower leaves, comparative $\mathrm{P}_{\mathrm{n}}$ in purple basil plants increased under treatments with mild green light proportions $(10 \%$ and $32 \%)$, but was unaffected in green basil plants (Fig. 2A). One hypothesis regarding the differences between two cultivars is a result of the lower quantum efficiency of blue light in purple basil plants compared with green basil plants. In purple basil plants, the relatively high concentration of flavonoids absorbs more blue light, which decreases the absorption of blue light by chloroplasts and subsequently decreases the photochemical energy transferred to reaction centers (Sun et al., 1998). This weakened the effects of blue light during photosynthesis in purple basil plants and resulted in unaffected $\mathrm{P}_{\mathrm{n}}$ in upper leaves under treatments with mild green light proportions (10\% and $32 \%$ ). The other hypothesis is a result of the different plant canopy density between green and purple basil plants. Under a denser plant canopy, lower leaves in plants have a greater capacity to absorb and use transmitted green light via the process of photoacclimation to shade, which causes increased synthesis of chlorophyll b (Nishio, 2000; Sun et al., 1998). Chlorophyll b has a CHO group instead of the $\mathrm{CH}_{3}$ group in chlorophyll a, and this small change in chemical structure shifts the absorption peak in the blue light wavelength to a weak absorption of green light, which aids in the acquisition of green light deeper in the plant canopy (Nishio, 2000). In our study, purple basil plants had a denser plant canopy, with seven pairs of leaves at harvest, compared with the five pairs of leaves in green basil plants, which strengthened the effects of green light in purple basil plants and led to increased $P_{n}$ in lower leaves. However, none of the previous studies - nor ours-evaluated the relationship between effects of green light and plant canopy density, which should be paid attention to in future studies.

Substituting green for red and/or blue light induced shade avoidance responses. It 

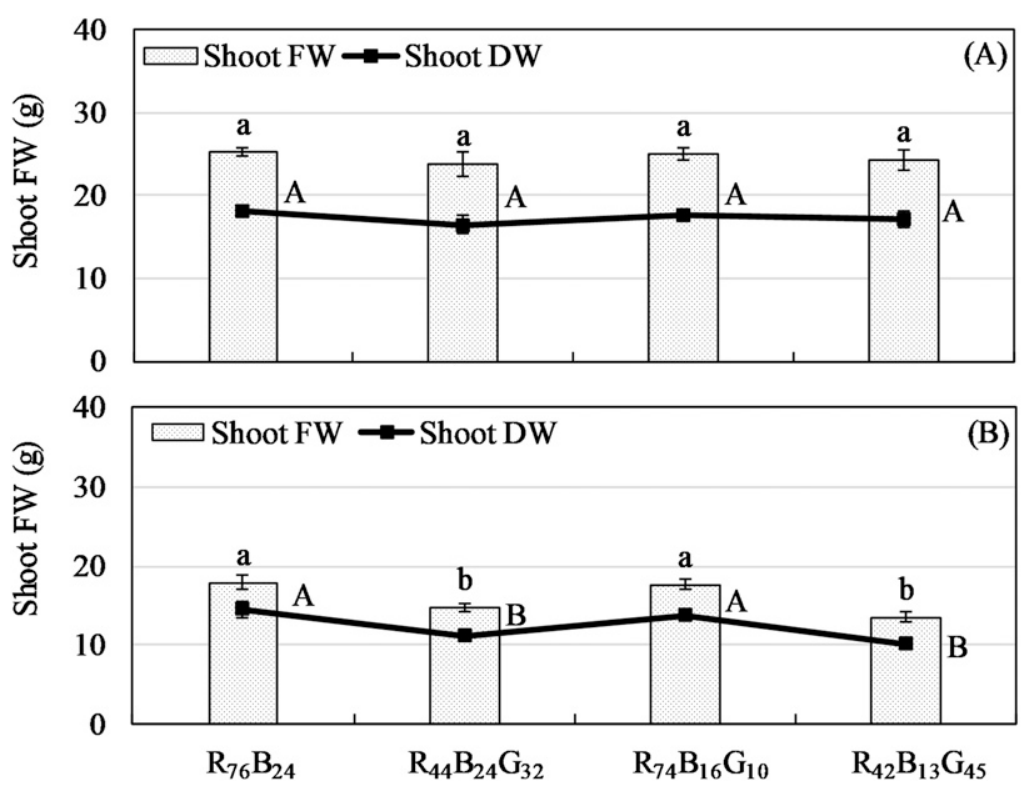

4.0

3.0

2.0

1.0

0.0

4.0

3.0

2.0

1.0

0.0

Fig. 5. Shoot fresh weight (FW) and dry weight (DW) of green basil 'Improved Genovese Compact' plants (A) and purple basil 'Red Rubin' plants (B) grown under different light-quality treatments: $\mathrm{R}_{76} \mathrm{~B}_{24}, \mathrm{R}_{44}$ $\mathrm{B}_{24} \mathrm{G}_{32}, \mathrm{R}_{74} \mathrm{~B}_{16} \mathrm{G}_{10}$, and $\mathrm{R}_{42} \mathrm{~B}_{13} \mathrm{G}_{45}$. Means followed by the same lower- and uppercase letters are not significantly different for shoot $\mathrm{FW}$ and DW, respectively, according to Student's $t$ mean comparison $(P<0.05)$. Bars represent se.

Table 2. Anthocyanin, phenolics, and flavonoids concentrations (conc.), and antioxidant capacity of green basil 'Improved Genovese Compact' and purple basil 'Red Rubin' plants grown under different lightquality treatments: including $\mathrm{R}_{76} \mathrm{~B}_{24}, \mathrm{R}_{44} \mathrm{~B}_{24} \mathrm{G}_{32}, \mathrm{R}_{74} \mathrm{~B}_{16} \mathrm{G}_{10}$, and $\mathrm{R}_{42} \mathrm{~B}_{13} \mathrm{G}_{45}$.

\begin{tabular}{llcccc}
\hline Cultivar & Treatment & $\begin{array}{c}\text { Anthocyanin } \\
\text { conc. }\left(\mathrm{mg} \cdot 100 \mathrm{~g}^{-1}\right)\end{array}$ & $\begin{array}{c}\text { Phenolics conc. } \\
\left(\mathrm{mg} \cdot \mathrm{g}^{-1}\right)\end{array}$ & $\begin{array}{c}\text { Flavonoids } \\
\text { conc. }\left(\mathrm{mg} \cdot \mathrm{g}^{-1}\right)\end{array}$ & $\begin{array}{c}\text { Antioxidant capacity } \\
\left(\mathrm{mg} \cdot 100 \mathrm{~g} \mathrm{~g}^{-1}\right)\end{array}$ \\
\hline Green basil & $\mathrm{R}_{76} \mathrm{~B}_{24}$ & $8.11 \mathrm{a}^{\mathrm{z}}$ & $2.06 \mathrm{a}$ & $1.77 \mathrm{ab}$ & $366 \mathrm{a}$ \\
& $\mathrm{R}_{44} \mathrm{~B}_{24} \mathrm{G}_{32}$ & $8.23 \mathrm{a}$ & $1.89 \mathrm{ab}$ & $1.84 \mathrm{a}$ & $353 \mathrm{a}$ \\
& $\mathrm{R}_{74} \mathrm{~B}_{16} \mathrm{G}_{10}$ & $7.58 \mathrm{ab}$ & $1.75 \mathrm{~b}$ & $1.67 \mathrm{bc}$ & $319 \mathrm{~b}$ \\
& $\mathrm{R}_{42} \mathrm{~B}_{13} \mathrm{G}_{45}$ & $6.95 \mathrm{~b}$ & $1.75 \mathrm{~b}$ & $1.54 \mathrm{c}$ & $306 \mathrm{~b}$ \\
Purple basil & $\mathrm{R}_{76} \mathrm{~B}_{24}$ & $13.36 \mathrm{~A}$ & $3.71 \mathrm{~A}$ & $2.29 \mathrm{AB}$ & $1,293 \mathrm{~A}$ \\
& $\mathrm{R}_{44} \mathrm{~B}_{24} \mathrm{G}_{32}$ & $14.15 \mathrm{~A}$ & $3.46 \mathrm{~B}$ & $2.16 \mathrm{~B}$ & $1,174 \mathrm{~B}$ \\
& $\mathrm{R}_{74} \mathrm{~B}_{16} \mathrm{G}_{10}$ & $13.33 \mathrm{~A}$ & $3.81 \mathrm{~A}$ & $2.34 \mathrm{~A}$ & $1,367 \mathrm{~A}$ \\
& $\mathrm{R}_{42} \mathrm{~B}_{13} \mathrm{G}_{45}$ & $12.92 \mathrm{~A}$ & $2.94 \mathrm{C}$ & $1.82 \mathrm{C}$ & $1,101 \mathrm{~B}$ \\
\hline
\end{tabular}

${ }^{\mathrm{z}}$ Means followed by the same lower- and uppercase letters are not significantly different for green and purple basil plants, respectively, according to Student's $t$ mean comparison $(P<0.05)$.

Subscript numbers indicate the proportions of red (R, 600-699 nm), blue (B, 400-499 nm), and green (G, $500-599 \mathrm{~nm}$ ) light in the total light intensity.

Table 3. Total amounts of anthocyanin, phenolics, flavonoids, and antioxidant capacity per plant of green basil 'Improved Genovese Compact' and purple basil 'Red Rubin' plants grown under different lightquality treatments: including $\mathrm{R}_{76} \mathrm{~B}_{24}, \mathrm{R}_{44} \mathrm{~B}_{24} \mathrm{G}_{32}, \mathrm{R}_{74} \mathrm{~B}_{16} \mathrm{G}_{10}$, and $\mathrm{R}_{42} \mathrm{~B}_{13} \mathrm{G}_{45}$.

\begin{tabular}{llcccc}
\hline & & \multicolumn{4}{c}{ Total amount of phytochemicals (mg/plant) } \\
\cline { 3 - 6 } Cultivar & Treatment & Anthocyanin & Phenolics & Flavonoids & Antioxidant capacity \\
\hline Green basil & $\mathrm{R}_{76} \mathrm{~B}_{24}$ & $1.63 \mathrm{a}^{2}$ & $41 \mathrm{a}$ & $35 \mathrm{a}$ & $73 \mathrm{a}$ \\
& $\mathrm{R}_{44} \mathrm{~B}_{24} \mathrm{G}_{32}$ & $1.54 \mathrm{a}$ & $35 \mathrm{~b}$ & $34 \mathrm{a}$ & $66 \mathrm{~b}$ \\
& $\mathrm{R}_{74} \mathrm{~B}_{16} \mathrm{G}_{10}$ & $1.51 \mathrm{a}$ & $35 \mathrm{~b}$ & $33 \mathrm{a}$ & $64 \mathrm{~b}$ \\
& $\mathrm{R}_{42} \mathrm{~B}_{13} \mathrm{G}_{45}$ & $1.32 \mathrm{~b}$ & $33 \mathrm{~b}$ & $29 \mathrm{~b}$ & $58 \mathrm{c}$ \\
Purple basil & $\mathrm{R}_{76} \mathrm{~B}_{24}$ & $1.90 \mathrm{~A}$ & $53 \mathrm{~A}$ & $33 \mathrm{~A}$ & $184 \mathrm{~B}$ \\
& $\mathrm{R}_{44} \mathrm{~B}_{24} \mathrm{G}_{32}$ & $1.66 \mathrm{~B}$ & $41 \mathrm{~B}$ & $25 \mathrm{~B}$ & $138 \mathrm{C}$ \\
& $\mathrm{R}_{74} \mathrm{~B}_{16} \mathrm{G}_{10}$ & $1.90 \mathrm{~A}$ & $54 \mathrm{~A}$ & $33 \mathrm{~A}$ & $19 \mathrm{~A}$ \\
& $\mathrm{R}_{42} \mathrm{~B}_{13} \mathrm{G}_{45}$ & $1.40 \mathrm{C}$ & $32 \mathrm{C}$ & $20 \mathrm{C}$ & $119 \mathrm{D}$ \\
\hline
\end{tabular}

${ }^{\mathrm{z}}$ Means followed by the same lower- and uppercase letters are not significantly different for green and purple basil plants, respectively, according to Student's $t$ mean comparison $(P<0.05)$.

Subscript numbers indicate the proportions of red (R, 600-699 nm), blue (B, 400-499 nm), and green (G, $500-599 \mathrm{~nm}$ ) light in the total light intensity.

has been widely reported that green light could induce shade avoidance responses, including promotion of stem and petiole elongation and hyponasty in arabidopsis (Folta and Maruhnich, 2007; Zhang et al., 2011). This was evidenced in our study: Treatments with greater green light proportions $(32 \%$ and $45 \%)$ resulted in increased stem and petiole elongation and decreased leaf thickness (Fig. 5). Similarly, Meng et al. (2019) reported that substituting blue light with green light increased petiole length in kale (Brassica oleracea). Shade avoidance responses induced by green light are likely mediated in two categories: cryptochrome-dependent and cryptochrome-independent pathways (Folta, 2004; Wang and Folta, 2013). Increased green light proportions significantly promoted hypocotyl elongation both in wild-type and phy $A$ phy $B$ seedlings, suggesting that green light-induced hypocotyl elongation occurs via a cryptochrome-mediated pathway instead of a phytochrome one (Sellaro et al., 2010). In addition to hypocotyl elongation, there are a number of blue and green light reversible effects regulated by a cryptochrome-dependent pathway, such as green light reversal of blue light-mediated stomatal opening (Frechilla et al., 2000; Kim et al., 2004; Talbott et al., 2006), inhibition of blue light-induced flowering induction (Banerjee et al., 2007), and blue light-stimulated anthocyanin synthesis (Banerjee et al., 2007; Zhang and Folta, 2012). On the other hand, some responses to green light persist in cry knockout mutant backgrounds, such as green light-regulated leaf architecture changes and plant adaptation, suggesting an unknown green light receptor through a novel mechanism (Sellaro et al., 2010; Zhang et al., 2011).

In our study, shoot FW and DW in purple basil plants decreased under treatments with greater green light proportions $(32 \%$ and $45 \%$ ), which was different from the results reported by Meng et al. (2019) and Kim et al. (2004), in which inclusion of green light resulted in greater shoot FW in kale and lettuce. One hypothesis of the difference might be a result of the different plant canopy architecture or canopy density (e.g., leaf area index) among lettuce, kale, and basil plants. Lettuce and kale plants are almost stemless and have rosette-like ground leaves or a folded-leaf structure during the vegetative stage, whereas basil plants have stems with much lower plant canopy density/compactness. The denser plant canopy of lettuce and kale plants would strengthen the effects of green light, resulting in increased light interception and photosynthesis of the entire plant canopy, and would lead to greater biomass accumulation. With regard to a less dense plant canopy, the detrimental effects caused by reduced red and/or blue light density may be equal to or may override the beneficial effects of green light and lead to unaffected or decreased biomass accumulation. For instance, green light treatment showed no effects on the growth of 'Cumlaude' cucumber (Cucumis sativus) seedlings (Hernandez et al., 2016), which also has a much lower plant canopy density/compactness than lettuce or kale plants. The other hypothesis causing the difference might be a result of the different compositions of green light (green light peak wavelength or ratios of short to long green light wavelength) used in studies. Research has shown that plant responses to short-wavelength green light 
(500-550 nm) and long-wavelength green light $(580-600 \mathrm{~nm}$, also defined as yellow light) are different (Dougher and Bugbee, 2001). The biomass accumulation of 'Red Fire' lettuce was the greatest under a G510 treatment (green light peak wavelength, 510 $\mathrm{nm}$ ) compared with treatments of G520 and G530 (green light peak wavelength, 524 and $532 \mathrm{~nm}$, respectively) at a $P P F D$ of 300 $\mu \mathrm{mol} \cdot \mathrm{m}^{-2} \cdot \mathrm{s}^{-1}$ (Johkan et al., 2012). It was also reported that an increased proportion of long-wavelength green light $(580-600 \mathrm{~nm}$, also defined as yellow light) decreased lettuce yield, perhaps as a result of suppression of chloroplast or chlorophyll formation (Bouly et al., 2007). Therefore, a broad-band green light source may result in different plant responses according to its peak wavelength or ratios of short to long green light wavelength.

Substituting green for red and/or blue light decreased secondary metabolite accumulation. Although mechanisms of how light quality affects plant secondary metabolism is still unclear, shared facts evidence that blue, green, and red lights are all involved in phytochemical accumulation through photoreceptor pathways (Dou et al., 2017; Zhang and Folta, 2012). The expression of key enzymes in the synthesis of phytochemicals, such as phenylalanine ammonia-lyase, chalcone synthase, dihydroflavonol 4-reductase, and polyphenol oxidase are reported to be regulated by blue and red lights (Li, 2010; Meng et al., 2004). However, little information is known on the regulation of phytochemicals by green light, in addition to green light reversal of blue lightinduced anthocyanin accumulation (Bouly et al., 2007; Zhang et al., 2011). Similar results were observed in our study: Concentrations of phenolics and flavonoids in green and purple basil plants were both decreased by green light radiation (Table 2). Consistently, Zhang and Folta (2012) reported that as green light intensity increased, the amount of anthocyanin in arabidopsis decreased to half the level present in plants grown under combined R\&B light. Also, Pennisi et al. (2019) reported that substituting green light for red light significantly decreased antioxidant capacity and flavonoid concentration in basil plants. It was postulated that the decreased phytochemical concentration under green light treatments is caused by the coactions of decreased red and/or blue light proportions and an increasing reversal of blue light-induced effects by green light.

Furthermore, regulation of phytochemical accumulation by light radiation was in speciesdependent and phytochemical-dependent manners. For example, blue light is more effective on accumulation of phytochemicals such as phenolics, flavonoids, and anthocyanins in Chinese foxglove (Rehmannia glutinosa) and perilla (Perilla frutescens) (Lee et al., 2014; Manivannan et al., 2015), whereas red light is more effective on accumulation of rosmarinic acid in basil plants (Shiga et al., 2009). In our study, phytochemical concentration in green basil plants showed no difference between treatments with a similar blue light proportion
$\left(\mathrm{R}_{76} \mathrm{~B}_{24}\right.$ and $\mathrm{R}_{44} \mathrm{~B}_{24} \mathrm{G}_{32}$ ), whereas in purple basil plants it showed no difference between treatments with a similar red light proportion $\left(\mathrm{R}_{76} \mathrm{~B}_{24}\right.$ and $\left.\mathrm{R}_{74} \mathrm{~B}_{16} \mathrm{G}_{10}\right)$ (Table 2). This indicates that the phytochemical accumulations in green and purple basil plants were predominated by blue and red light, respectively, regardless of the inclusion of green light. Moreover, the proportions of blue and red light played a major role in regulating phytochemical accumulation in basil plants, instead of the absolute red or blue light intensity.

\section{Conclusion}

Inclusion of green light in growth light sources increased the $P_{n}$ in lower leaves in purple basil plants, but showed no effects on green basil plants as a result of different phytochemical composition and plant canopy density. Green light induced shade avoidance responses such as stem and petiole elongation, decreased leaf thickness, and reduced chlorophyll concentration in both basil cultivars. However, greater green light proportions decreased the shoot FW and DW in purple basil plants, whereas the inclusion of green light showed no effects on the shoot FW and DW in green basil plants. In addition, treatments with greater green light proportions decreased the phytochemical concentration such as phenolics, flavonoids, and anthocyanin in basil plants. These results suggest that the inclusion of a small proportion of green light in growth light sources could produce a pleasant environment for growers and plants without reducing the yield and phytochemical contents in basil plants. Further studies are needed to determine the optimal green light proportions for plant production with different canopy densities and phytochemical compositions, and more tests are needed with different green light peak wavelengths or ratios of short to long green light wavelengths.

\section{Literature Cited}

Amaki, W., N. Yamazaki, M. Ichimura, and H. Watanabe. 2011. Effects of light quality on the growth and essential oil content in sweet basil. Acta Hort. 907:91-94.

Arnao, M.B., A. Cano, and M. Acosta. 2001. The hydrophilic and lipophilic contribution to total antioxidant activity. Food Chem. 73(2):239244

Banerjee, R., E. Schleicher, S. Meier, R.M. Viana, R. Pokorny, M. Ahmad, R. Bittl, and A. Batschauer. 2007. The signaling state of Arabidopsis cryptochrome 2 contains flavin semiquinone. J. Biol. Chem. 282(20):14916-14922.

Bantis, F., S. Smirnakou, T. Ouzounis, A. Koukounaras, N. Ntagkas, and K. Radoglou. 2018. Current status and recent achievements in the field of horticulture with the use of light emitting diodes (LEDs). Scientia Hort. 235:437451.

Bian, Z.H., R.F. Cheng, Q.C. Yang, J. Wang, and C. Lu. 2016. Continuous light from red, blue, and green light-emitting diodes reduces nitrate content and enhances phytochemical concentrations and antioxidant capacity in lettuce. J. Amer. Soc. Hort. Sci. 141:186-195.
Bian, Z.H., Q.C. Yang, T. Li, R. Cheng, Y. Barnett, and C. Lu. 2018. Study of the beneficial effects of green light on lettuce grown under shortterm continuous red and blue light-emitting diodes. Physiol. Plant. 164(2):226-240.

Bouly, J.P., E. Schleicher, M. Dionisio-Sese, F. Vandenbussche, D. Van Der Straeten, N. Bakrim, S. Meier, A. Batschauer, P. Galland, and R. Bittl. 2007. Cryptochrome blue light photoreceptors are activated through interconversion of flavin redox states. J. Biol. Chem. 282(13):9383-9391.

Brazaityte, A., A. Virsile, G. Samuoliene, J. Jankauskiene, S. Sakalauskiene, R. Sirtautas, A. Novickovas, L. Dabasinskas, V. Vastakaite, J. Miliauskiene, and P. Duchovskis. 2016. Light quality: Growth and nutritional value of microgreens under indoor and greenhouse conditions. Proc. VIII Intl Sym. Light Hort 1134: 277-284.

Connor, A.M., J.J. Luby, and C.B. Tong. 2002. Variability in antioxidant activity in blueberry and correlations among different antioxidant activity assays. J. Amer. Soc. Hort. Sci. 127: 238-244.

Dou, H., G. Niu, M. Gu, and J.G. Masabni. 2017. Effects of light quality on growth and phytonutrient accumulation of herbs under controlled environments. Horticulturae 3(2):36.

Dou, H., G. Niu, M. Gu, and J.G. Masabni. 2018. Responses of sweet basil to different daily light integrals in photosynthesis, morphology, yield, and nutritional quality. HortScience 53:496503.

Dougher, T.A. and B. Bugbee. 2001. Evidence for yellow light suppression of lettuce growth. Photochem. Photobiol. 73(2):208-212.

Fan, X., J. Zang, Z. Xu, S. Guo, X. Jiao, X. Liu, and Y. Gao. 2013. Effects of different light quality on growth, chlorophyll concentration and chlorophyll biosynthesis precursors of non-heading Chinese cabbage (Brassica campestris L.). Acta Physiol. Plant. 35(9):2721-2726.

Folta, K.M. 2004. Green light stimulates early stem elongation, antagonizing green light-mediated growth inhibition. Plant Physiol. 135(3):14071416.

Folta, K.M. and S.A. Maruhnich. 2007. Green light: A signal to slow down or stop. J. Expt. Bot. 58(12):3099-3111.

Frechilla, S., L.D. Talbott, R.A. Bogomolni, and E. Zeiger. 2000. Reversal of blue light-stimulated stomatal opening by green light. Plant Cell Physiol. 41(2): 171-176.

He, J., L. Qin, Y. Liu, and T.W. Choong. 2015. Photosynthetic capacities and productivity of indoor hydroponically grown Brassica alboglabra Bailey under different light sources. Amer. J. Plant Sci. 6(04):554.

Hernandez, R., T. Eguchi, and C. Kubota. 2016. Growth and morphology of vegetable seedlings under different blue and red photon flux ratios using green light-emitting diodes as solesource lighting. Proc. VIII Intl. Sym. Light Hort. 1134:195-200.

Johkan, M., K. Shoji, F. Goto, S.N. Hashida, and T. Yoshihara. 2012. Effect of green light wavelength and intensity on photomorphogenesis and photosynthesis in Lactuca sativa. Environ. Exp. Bot. 75:128-133.

Kasperbauer, M. 1971. Spectral distribution of light in a tobacco canopy and effects of endof-day light quality on growth and development. Plant Physiol. 47(6):775-778.

Kim, H.H., G.D. Goins, R.M. Wheeler, and J.C. Sager. 2004. Green-light supplementation for enhanced lettuce growth under red- and blue- 
light-emitting diodes. HortScience 39:16171622.

Kudo, R., Y. Ishida, and K. Yamamoto. 2011. Effects of green light irradiation on induction of disease resistance in plants. Acta Hort. 907:251-254

Lee, J.S., C.A. Lee, Y.H. Kim, and S.J. Yun. 2014. Shorter wavelength blue light promotes growth of green perilla (Perilla frutescens). Intl. J. Agr. Biol. 16(6): 1177-1182.

Li, Q. 2010. Effects of light quality on growth and phytochemical accumulation of lettuce and Salvia miltiorrhiza bunge. Northwest A\&F University, Shanxi, China. PhD Diss.

Lian, M.L., H. Murthy, and K.Y. Paek. 2002. Effects of light emitting diodes (LEDs) on the in vitro induction and growth of bulblets of Lilium oriental hybrid 'Pesaro'. Scientia Hort. 94(3-4):365-370.

Manivannan, A., P. Soundararajan, N. Halimah, C.H. Ko, and B.R. Jeong. 2015. Blue LED light enhances growth, phytochemical contents, and antioxidant enzyme activities of Rehmannia glutinosa cultured in vitro. Hort. Environ. Biotechnol. 56(1):105-113.

Martineau, V., M. Lefsrud, M.T. Naznin, and D.A. Kopsell. 2012. Comparison of light-emitting diode and high-pressure sodium light treatments for hydroponics growth of Boston lettuce. HortScience 47:477-482.

McCree, K.J. 1972. The action spectrum, absorptance and quantum yield of photosynthesis in crop plants. Agr. Meteorol. 9:191-216.

Meng, Q., N. Kelly, and E.S. Runkle. 2019. Substituting green or far-red radiation for blue radiation induces shade avoidance and promotes growth in lettuce and kale. Environ. Exp. Bot. 162:383-391.

Meng, X., T. Xing, and X. Wang. 2004. The role of light in the regulation of anthocyanin accumulation in Gerbera hybrida. Plant Growth Regulat. 44(3):243-250.

Nhut, D.T., T. Takamura, H. Watanabe, K. Okamoto, and M. Tanaka. 2003. Responses of strawberry plantlets cultured in vitro under superbright red and blue light-emitting diodes (LEDs). Plant Cell Tissue Organ Cult. 73(1):43-52.

Nishio, J. 2000. Why are higher plants green? Evolution of the higher plant photosynthetic pigment complement. Plant Cell Environ. 23(6):539-548.

Ohashi-Kaneko, K., M. Takase, N. Kon, K. Fujiwara, and K. Kurata. 2007. Effect of light quality on growth and vegetable quality in leaf lettuce, spinach and komatsuna. Environ. Control Biol. 45(3):189-198.

Paradiso, R., E. Meinen, J.F. Snel, P. De Visser, W. Van Ieperen, S.W. Hogewoning, and L.F. Marcelis. 2011. Spectral dependence of photosynthesis and light absorptance in single leaves and canopy in rose. Scientia Hort. 127(4):548554.

Pennisi, G., S. Blasioli, A. Cellini, L. Maia, A. Crepaldi, I. Braschi, F. Spinelli, S. Nicola, J.A. Fernandez, and C. Stanghellini. 2019. Unravelling the role of red:blue LED lights on resource use efficiency and nutritional properties of indoor grown sweet basil. Front. Plant Sci. 10:305.

Piovene, C., F. Orsini, S. Bosi, R. Sanoubar, V. Bregola, G. Dinelli, and G. Gianquinto. 2015. Optimal red:blue ratio in LED lighting for nutraceutical indoor horticulture. Scientia Hort. 193:202-208.

Sager, J., W. Smith, J. Edwards, and K. Cyr. 1988. Photosynthetic efficiency and phytochrome photoequilibria determination using spectral data. Trans. ASAE 31(6):1882-1889.

Sellaro, R., M. Crepy, S.A. Trupkin, E. Karayekov, A.S. Buchovsky, C. Rossi, and J.J. Casal. 2010. Cryptochrome as a sensor of the blue/green ratio of natural radiation in Arabidopsis. Plant Physiol. 154(1):401-409.

Shiga, T., K. Shoji, H. Shimada, S.N. Hashida, F. Goto, and T. Yoshihara. 2009. Effect of light quality on rosmarinic acid content and antioxidant activity of sweet basil, Ocimum basilicum L. Plant Biotechnol. 26(2):255-259.

Smith, H.L., L. Mcausland, and E.H. Murchie. 2017. Don't ignore the green light: Exploring diverse roles in plant processes. J. Expt. Bot. 68(9):2099-2110.

Sun, J., J.N. Nishio, and T.C. Vogelmann. 1998. Green light drives $\mathrm{CO}_{2}$ fixation deep within leaves. Plant Cell Physiol. 39(10):1020-1026.

Talbott, L.D., J.W. Hammad, L.C. Harn, V.H. Nguyen, J. Patel, and E. Zeiger. 2006. Reversal by green light of blue light-stimulated stomatal opening in intact, attached leaves of Arabidopsis operates only in the potassium-dependent, morning phase of movement. Plant Cell Physiol. 47(3):332-339.

Talbott, L.D., G. Nikolova, A. Ortiz, I. Shmayevich, and E. Zeiger. 2002. Green light reversal of blue-light-stimulated stomatal opening is found in a diversity of plant species. Amer. J. Bot. 89(2):366-368.

Tamulaitis, G., P. Duchovskis, Z. Bliznikas, K. Breive, R. Ulinskaite, A. Brazaityte, A. Novickovas, and A. Zukauskas. 2005. High-power lightemitting diode based facility for plant cultivation. J. Phys. D Appl. Phys. 38(17):3182.

Terashima, I., T. Fujita, T. Inoue, W.S. Chow, and R. Oguchi. 2009. Green light drives leaf photosynthesis more efficiently than red light in strong white light: Revisiting the enigmatic question of why leaves are green. Plant Cell Physiol. 50(4):684-697.

Vogelmann, T. and T. Han. 2000. Measurement of gradients of absorbed light in spinach leaves from chlorophyll fluorescence profiles. Plant Cell Environ. 23(12):1303-1311.

Wang, Y. and K.M. Folta. 2013. Contributions of green light to plant growth and development. Amer. J. Bot. 100(1):70-78.

$\mathrm{Xu}$, C.P. and B.Q. Mou. 2016. Responses of spinach to salinity and nutrient deficiency in growth, physiology, and nutritional value. J. Amer. Soc. Hort. Sci. 141:12-21.

Zhang, T. and K.M. Folta. 2012. Green light signaling and adaptive response. Plant Signal. Behav. 7(1):75-78.

Zhang, T., S.A. Maruhnich, and K.M. Folta. 2011 Green light induces shade avoidance symptoms. Plant Physiol. 157(3):1528-1536. 